\title{
Titanium scaffold osteogenesis in healthy and osteoporotic rats is improved by the use of low-level laser therapy (GaAlAs)
}

\author{
Luana Marotta Reis de Vasconcellos ${ }^{1}$ • Mary Anne Moreira Barbara ${ }^{1}$. \\ Emanuel da Silva Rovai ${ }^{2}$ - Mariana de Oliveira França ${ }^{1}$ - Zahra Fernandes Ebrahim ${ }^{1}$. \\ Luis Gustavo Oliveira de Vasconcellos ${ }^{3}$ - Camila Deco Porto ${ }^{1}$. \\ Carlos Alberto Alves Cairo ${ }^{4}$
}

Received: 27 August 2015 / Accepted: 23 March 2016/Published online: 7 April 2016

(C) Springer-Verlag London 2016

\begin{abstract}
The present study aimed to assess the effects of low-level laser therapy (GaAlAs) on the bone repair process within titanium scaffolds in the femurs of healthy and osteoporotic rats. Fifty-six rats were divided into four groups: group Sh: SHAM animals that received scaffolds; group LSh: SHAM animals that received scaffolds and were subjected to laser therapy; group OV: ovarietomized (OVX) animals that received scaffolds; and group LOV: OVX animals that received scaffolds and were subjected to laser therapy. Thirty days following ovariectomy or sham surgery, scaffolds were implanted in the left femurs of all animals in the study. Immediately after opening the surgical site, the inner part of the surgical cavity was stimulated with low-level laser (GaAlAs). In addition to this procedure, the laser group was also subjected to sessions of low-level laser therapy (LLLT) at 48-h intervals, with the first session performed immediately
\end{abstract}

Luana Marotta Reis de Vasconcellos

luanamrv@gmail.com

1 Department of Bioscience and Oral Diagnosis, Institute of Science and Technology, Univ Estadual Paulista (UNESP), Av. Engenheiro Francisco José Longo, 777, São José dos Campos, SP, Brazil CEP 12245-000

2 Department of Stomatology, Division of Periodontics, School of Dentistry, University of São Paulo, USP, Av. Lineu Prestes, 2227, São Paulo, SP, Brazil CEP 05508-000

3 Department of Prosthodontics and Dental Materials, Institute of Science and Technology, Univ Estadual Paulista (UNESP), Av. Eng. Francisco José Longo, 777, São José dos Campos, SP, Brazil CEP 12245-000

4 Division of Materials, Air and Space Institute, CTA, Praça Mal. do Ar Eduardo Gomes 14, São José dos Campos 12904-000, SP, Brazil after surgery. The rats were sacrificed at 2 and 6 weeks, time in which femur fragments were submitted for histological and histomorphometric examination, and skin tissue above the scaffold was submitted to histological analysis. At the end of the study, greater bone formation was observed in the animals submitted to LLLT. At 2 and 6 weeks, statistically significant differences were observed between LSh and Sh groups $(p=0.009$ and 0.0001$)$ and LOV and OV ( $p=0.0001$ and $0.0001)$, respectively. No statistical difference was observed when assessing the estrogen variable. On the basis of our methodology and results, we conclude that LLLT improves and accelerates bone repair within titanium scaffolds in both ovariectomized and healthy rats, when compared to animals not subjected to radiation.

Keywords Dental implant - Osseointegration - Titanium · Ovariectomy $\cdot$ Laser therapy

\section{Introduction}

Titanium scaffolds are considered suitable biomaterials for bone tissue engineering, as they induce self-regeneration of damaged bone tissue due to their high porosity, physical strength, biocompatibility, and osteoconductive properties, such as progenitor cells and growth factors, allowing the body to restore structure and functionality. As a result, titanium scaffolds provide greater contact between the bone and the biomaterial, which is helpful in the regeneration of critical bone defects, in filling tumor removal areas, and in patients with bone metabolism changes [1-3].

Several previous studies have showed that creating threedimensional porous structures induces bone ingrowth at the implant surface, resulting in a more effective osseointegration [1, 4-6]. Furthermore, interconnected pores allow new vascularization, tissue proliferation, and increase the contact surface 
between tissue and implant, improving the prosthesis anchorage to the bone, preventing its loss [1, 4, 7]. Several manufacturing processes of porous titanium are known, such as sintering same sized beads or fibers by isostatic press, sintering loosely packed powders, the atomization process, and powder metallurgy [4, 8-10]. Our previous studies have shown that powder metallurgy is able to produce Ti foams with pore sizes adjusted within the range required for bone ingrowth $[1,4]$.

Although titanium scaffolds present high rates of success, they still required a degree of improvement, particularly in their capacity to selectively influence and guide cell and tissue events at the implantation site, once their success depends on the patient's overall health [11]. Osteoporosis is one of the most common osteopathies in the world and is considered a systemic skeleton disease, marked by a reduction in bone mass, caused by the imbalance between bone reabsorption and new bone formation, which leads to increased bone fragility and a greater risk of fractures [12]. Under osteoporotic conditions, there are both a reduction in bone formation and an increase in bone reabsorption, aspects that can compromise the primary stability as well as the final osseointegration of titanium implants [13].

Alternative in vivo bone engineering uses a combination of titanium scaffolds with low-level laser therapy (LLLT) on implant sites $[14,15]$. Low-level laser therapy is effective in stimulating bone growth prior to implant surgery in patients who suffered significant bone loss, and in those presenting metabolic disorders that affect bone remodeling or successful osseointegration, such as osteoporosis [16]. Moreover, LLLT is able to accelerate new bone formation, thus increasing osteoblastic activity, vascularization, and the distribution of collagen fibers, as well as their antibacterial and immunological effects $[17,18]$. Other positive effects of low-level laser therapy include blood flow stimulation in peri-implant sites, improved contact between implant and bone surfaces, and faster bone maturation [19, 20]. Low-level laser therapy has also been used in several clinical procedures, including soft and hard tissue scar treatment, as it accelerates the healing process, promotes antiinflammatory and analgesic effects, stimulates the immune system, and contributes to cellular regeneration [19]. Improving laser therapy currently represents one of the most promising research fields to enable treatment options that both accelerate the osseointegration of biomaterials and adequately prepare implant sites [21].

We hypothesize that laser therapy can improve bone regeneration within titanium scaffolds in rats as an experimental model for osteoporosis. To conduct this study, we inserted titanium scaffolds into the femurs of ovariectomized rats, submitting some of the animals to irradiation on the surgical cavities, as well as transcutaneously.

\section{Materials and methods}

\section{Scaffolds}

Cylindrical titanium scaffolds $(2.5 \mathrm{~mm}$ length $\times 3.0 \mathrm{~mm}$ diameter) were manufactured by powder metallurgy (Fig. 1) at the Department of Materials of the Aerospace Institute at CTA (Brazilian Aerospace Technical Center in São José dos Campos, SP, Brazil). The scaffolds were produced using pure Ti powder formed by hydrogenation and dehydrogenation (HDDH) with purity $\geq 99.5 \%$ and particle size $\leq 8 \mu \mathrm{m}$. The Ti powder used was developed at the General Command of CTA and the Materials Division (AMR) of the Institute of Aeronautics and Space (IAE). The organic additive urea was used as a space holder, with particle size ranging from 177 to $250 \mu \mathrm{m}$. The weight ratio of Ti powder to space holder was calculated to obtain defined porosities of $40 \%$ pores with an average diameter of $180 \mu \mathrm{m}$.

Optical quantitative metallography and the Image Tool software were used to evaluate the porous structures. The scaffolds were cut into five sections, with four images taken of each section at $\times 100$ magnification, totaling $20 \mathrm{im}$ ages of each sample. The microstructure and the topography of the porous surfaces were characterized by scanning electron microscopy (SEM) (LEO 435 VPI, Montreal, QC, Canada).

Prior to implantation, the scaffolds were cleaned by sonication for $30 \mathrm{~min}$ in a $1 \%(v / v)$ detergent solution and distilled water $(\mathrm{dH} 2 \mathrm{O})$, then rinsed three times in $\mathrm{dH} 2 \mathrm{O}$. Following cleaning, they were packaged in sterilizable pouches (Cristófoli Biossegurança, Campo Mourão, Paraná, Brazil) and sterilized in an autoclave (Cristófoli Biossegurança, Campo Mourão, Paraná, Brazil) at $121^{\circ}$ for 15 min.

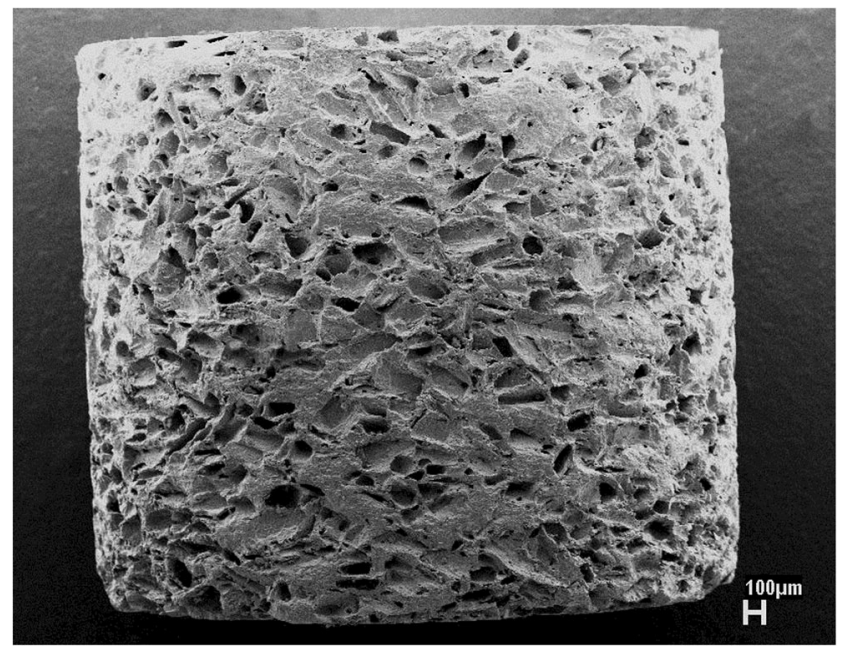

Fig. 1 Macrostructure of a titanium scaffold, manufactured by a powder metallurgy 


\section{Animals}

Fifty-six 90-day-old female rats weighing $300 \mathrm{~g}$ were used in this study. The rats were supplied by the Animal Center of the Sao Jose dos Campos School of Dentistry and were kept in cages, fed with commercial pet food (Guabi Nutrilabor) and water ad libitum. This study was approved by the Ethics in Research Committee of the Graduate School of Dentistry of Sao Jose dos Campos, UNESP (process number 040/2007).

Initially, the rats were randomly allocated into two groups $(n=28)$. Subsequently, one group was submitted to Sham surgery (simulate ovariectomy) while the other to ovariectomy (OVX). This was done so that ovarian hormones were only present in one of the groups. Each group was then subdivided into four subgroups, according to whether or not they were submitted to laser radiation: (a) group Sh: SHAM (control) animals that received scaffolds; (b) group LSh: SHAM animals that received scaffolds + laser therapy; (c) group OV: OVX animals that received scaffolds; and (d) group LOV: OVX animals that received scaffolds + laser therapy.

Both ovariectomy or sham surgery procedures and the insertion of titanium scaffolds were performed as described in our previous study [22]. Thirty days following ovariectomy or sham surgery, all animals received the scaffold measuring $2.5 \mathrm{~mm}$ in length and $3.0 \mathrm{~mm}$ in diameter in the left femur. Immediately after opening the surgical site, the inside of the surgical cavity was stimulated with lowlevel laser. The LLLT source used was a gallium aluminum arsenide (GaAlAs) semiconductor diode laser device (Easy Laser, Clean Line ${ }^{\circledR}$, Taubaté, SP, Brazil; $\mu=780 \mathrm{~nm}$; infrared, continuous wave, $P=40 \mathrm{~mW} ; \Theta=0.69 \mathrm{~cm} ; t=1 \mathrm{~min}$ $40 \mathrm{~s}$ ). The laser beam was delivered in continuous emission mode through an optic fiber directly onto the bone (surgical cavity).

After the insertion of the titanium scaffold and suture of the muscle and the skin, all of the rats received an antibiotic (Pentabiotico ${ }^{\circledR}$, Fort Dodge Saúde Animal, São Paulo, Brazil). The animals were inspected daily for clinical signs of complications or adverse reactions. Immediately after surgery, the laser group was subjected to transcutaneously sessions of LLLT, at regular 48-h intervals. A dose of $4 \mathrm{~J} /$ $\mathrm{cm}^{2}$ was applied to four points around the cavity, making a total of $16 \mathrm{~J} / \mathrm{cm}^{2}$ per session and a total treatment dose of $112 \mathrm{~J} / \mathrm{cm}^{2}$.

All rats were submitted to the same type of stress during the experiment. The groups that did not receive radiation, both sham and ovariectomized rats, were submitted to the same type of manipulation as the irradiated rats, but with the laser turned off. The rats were sacrificed using an anesthetic overdose administered intramuscularly either at 2 or 6 weeks after implantation (seven rats for each experimental period).

\section{Histological and histomorphometric analysis}

Following euthanasia, the femur fragments were submitted for histological and histomorphometric examination, also following procedure described in our previous studies [1, 22, 23]. At the time of euthanasia, the scaffolds were examined macroscopically and none presented mobility.

A semi-quantitative evaluation of scaffold-bone neoformation was carried out. The percentage of new bone at the bone-implant interface was evaluated in two sections of each scaffold. Therefore, two fields of each section were counted, representing the medial and distal interface of the scaffold. The evaluation was performed on calibrated digital pictures at $\times 10$ magnification (Axioplan 2, Carls Zeiss, Germany). New bone rate was calculated using ImageJ software (NIH). Two trained examiners blinded to the other groups examined each specimen independently.

The skin tissue above each scaffold was submitted for histological analysis. The skin tissue samples were fixated in $10 \%$ neutral buffered formalin (NBF) for a period of $48 \mathrm{~h}$. The samples were then cut transversally by hemisection at the center of the surgical incision, with each fragment immersed in paraffin, in the direction of the incision surface, and submitted to routine histological analysis. Ten semi-serial sections were obtained from each block, measuring an average of $4 \mu \mathrm{m}$ in thickness and $60 \mu \mathrm{m}$ between each level. We applied a hematoxylin
Fig. 2 SEM photos of a titanium scaffold: interconnected pores, micro-, and macropores

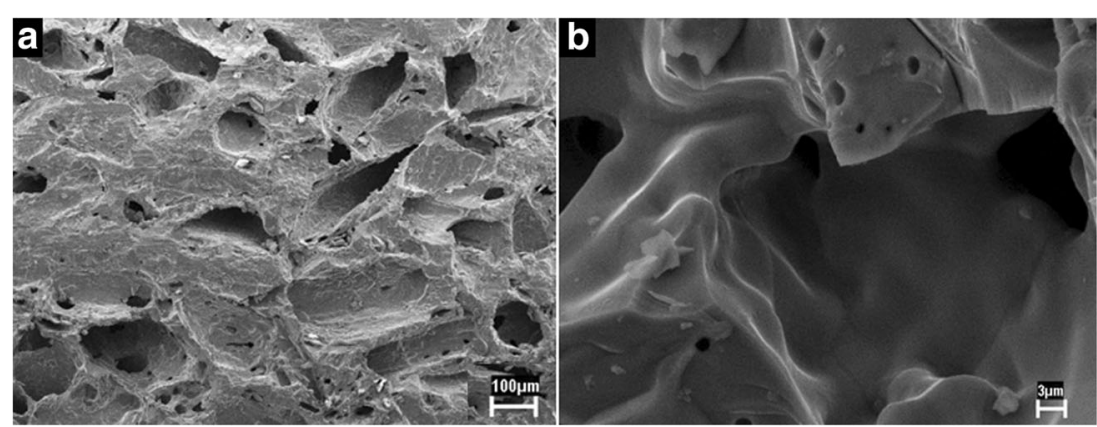


Fig. 3 Histological section of the bone-scaffold interface at

2 weeks. a Groups that received LLLT show pores partially filled with bone ingrowth (white arrow). b Groups that did not receive LLLT exhibit pores with no ingrowth (white arrow).

Toluidine blue staining photomicrographs
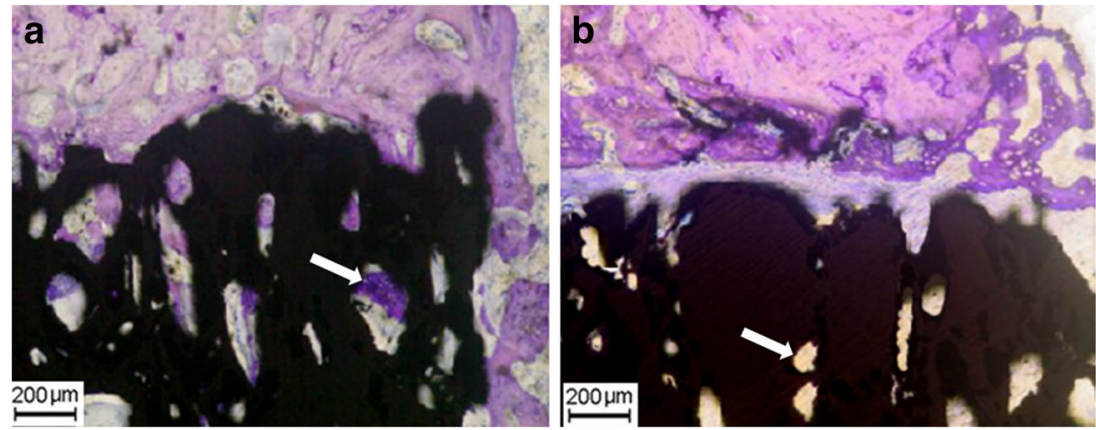

and eosin stain (HE-Merck \& Co, Inc.) before submitting the sections for histological analysis under light microscope.

\section{Statistical analysis}

Histomorphometric data analysis was performed in GRAPHPAD PRISM 6.0. The one-way ANOVA followed by Tukey's post hoc test was used for data processing. The results followed normal distributions and were expressed as mean value \pm standard deviation (SD). The difference was considered statistically significant at a $p$ value of $<0.05$.

\section{Results}

\section{Titanium scaffold characterization}

Figure 2 shows the titanium scaffold structure by SEM. The porous structure exhibits different types of pores, with interconnected macro- and micropores. The image reveals small and isolated pores that resulted from volume shrinkage during the sintering process of the titanium powders, and larger interconnecting pores, which were specifically included in the manufacturing process for their appropriateness in relation to the ingrowth of new bone tissue and the transportation of body fluids.

\section{Experimental groups}

All of the animals presented satisfactory postoperative results, with no surgical complications. During clinical evaluation, no macroscopic or microscopic signs of infection were found. The scaffolds were firmly attached to the bone, and it was not possible to remove them manually.

The success of ovariectomy process was confirmed by the failure to detect ovaries and by the clear presence of uterine tube atrophy.

\section{Histological and histomorphometric examination}

The qualitative microscopic analysis confirmed the presence of new bone formation in all samples. At 2 weeks, the bone tissue of the animals that received radiation was more cellularized than the animals that did not received LLLT, which instead presented a more immature bone tissue. The presence of gaps and osteocytes, as well as the migration of bone tissue to the inner part of the pores on the implant surface, was observed irrespective of treatment, although the pores were partly filled by bone only in the animals that received laser treatment (Fig. 3a, b). At 6 weeks, most implant pores were filled by new bone tissue, whether or not the sites were submitted to radiation (Fig. 4).

Laser therapy leads to greater new bone formation at all assessment periods when mean values were compared exclusive of the estrogen variable (Fig. 5). At 2 and 6 weeks, a statistically significant difference was found between LSh and Sh $(p=0.009$ and 0.0001$)$, and LOV and OV $(p=0.0001$ and 0.0001$)$, respectively. Despite animals with no estrogen having showed lower new bone formation values at both periods, when the estrogen variable was taken into account, no statistically significant difference was found between OV and Sh $(p=0.15)$, and LOV and LSh $(p=0.16)$ at 2 weeks. However, at 6 weeks, a statistically significant

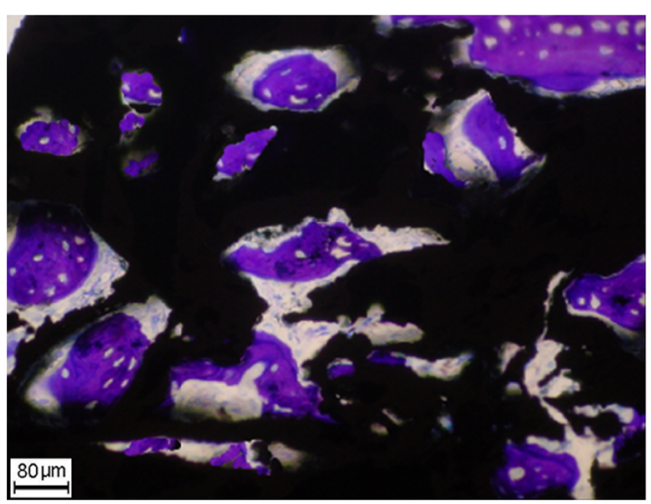

Fig. 4 Histological section of a titanium scaffold at 6 weeks showing bone ingrowth within its pores, irrespective of group. Toluidine blue staining photomicrographs 
Fig. 5 Percentage of bone formation within the titanium scaffold. a Period at 2 weeks. b Period at 6 weeks. *Statistically significant difference $(p<0.05)$ ANOVA (one-way)-Tukey's test

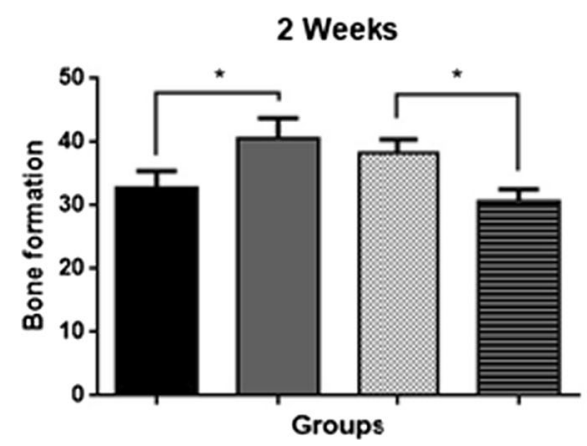

6 Weeks

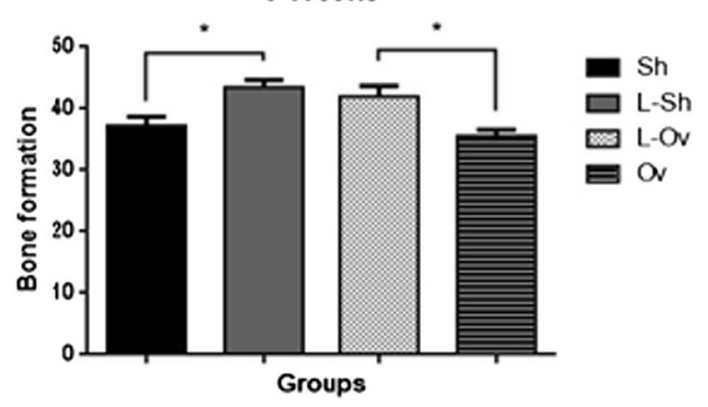

difference was found between OV and Sh $(p=0.045)$, but not when comparing LOV and LSh $(p=0.10)$.

\section{Skin tissue quantity analysis}

The highest level of cellularity in granulation tissue was seen at 2 weeks in most irradiated animals, with young and bulky fibroblasts, an absence of inflammatory cells, and the better arrangement of collagen fibrils (Fig. 6a). Conversely, some of the animals not submitted to radiation showed areas with disorganized epithelium and underlying connective tissue, with the presence of chronic inflammatory cells, various congested blood vessels, and delicate collagen fibrils (Fig. 6b). Nonetheless, difference between OVZ and Sham animals in this period was not observed. At 6 weeks, the histological pattern was similar for all animals.

\section{Discussion}

Several experimental studies have used titanium scaffolds to shorten the period of bone regeneration $[1-3,5-7,14]$. To stimulate bone healing, the association of scaffolds with different materials, e.g., autologous marrow cells, demineralized bone matrix, vitamin D analog, and cultured periosteal cells [24-26], or with laser therapy can be used [20, 22, 27-29].
In the present study, the quality and quantity of bone regeneration within titanium scaffolds inserted in OVX rats submitted or not to laser therapy were analyzed, as well as the skin tissue on the surgical cavity. We observed that there was greater new bone formation in the irradiated animals, with statistically significant differences to animals not submitted to radiation, regardless of the presence of estrogen, in both short and long periods of healing. The skin tissue also showed better results in the irradiated animals, with more organized collagen fibrils and an accelerated healing process.

Osteoporosis is a clinically and epidemiologically relevant disease due to its high incidence and mortality rates, considerable economic and social costs, besides a decreased in the quality of life of those who suffer it. As the natural healing process in osteoporotic bones is more prolonged [30, 31], some researchers use osteoporotic rat models to develop alternative therapies that stimulate bone healing $[22,29,30,32$, 33]. The ovariectomized rats showed characteristics of bone loss similar to those found in postmenopausal women [32] and are widely available, have a low maintenance cost, and are easy to handle [30]. In this study, we subjected half of the rats to ovariectomy by means of an accepted model of postmenopausal osteoporosis [22, 27-29, 33]. Thirty days following ovariectomy, we started the study of the femoral necks, in accordance with the method described by Li et al. (1997) [34] and Lelovas et al. (2008) [30], which states this is the time required to induce osteoporosis with statistically

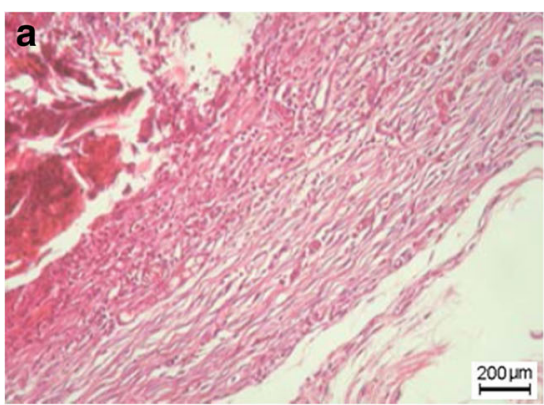

Fig. 6 Histological section, at 2 weeks. a Irradiated groups show more cellularity in granulation tissue with young and bulky fibroblasts, absence of inflammatory cells, and better arrangement of collagen fibrils. b

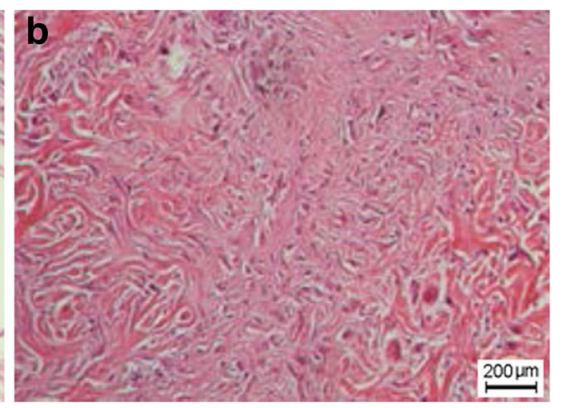

Groups not submitted to radiation show an immature arrangement of collagen fibrils and the presence of chronic inflammatory cells. Hematoxylin and eosin staining photomicrographs 
significant bone loss. Contrary to what was expected, no statistically significant difference in bone repair was found between OVX and Sham animals at 2 weeks (45 days after ovariectomy surgery), but similar results were observed by Pires-Oliveira et al. (2010) [27] and Prado et al. (2012) [35]. However, differences were found at 6 weeks. These results may be due to changes in the cortical bone, which take longer than other bone tissues to heal [36].

The key purpose of the use of titanium scaffolds is to enable better osseointegration through bone ingrowth. The pores in which growth happens are three-dimensional, leading to stronger fixation between the scaffold and the bone, due to the increased bone-implant contact caused by the configuration of the surfaces involved [1, 4-6]. In our study, the titanium scaffolds were produced by powder metallurgy and presented a complex porous structure with interconnected pores, resembling those of cancellous bone.

LLLT has been used to achieve better osseointegration and is able to promote greater new bone formation [22,37], as well as to reduce the pain associated with bone tissue injuries [37]. Positive results may be mainly credited to the capacity LLLT has to modulate inflammation, accelerate the cellular proliferation, enhance bone repair, and promote the differentiation of mesenchymal stem cells and osteoblastic differentiation [19]. Some studies also report that LLLT allows a decrease in the numbers of osteoclasts $[29,38]$, being an important factor to osteoporotic animals.

In addition to bone regeneration, LLLT has been used in soft tissue scar treatment, as it stimulates the immune system and accelerates the healing process by increasing the activity of cells such as fibroblasts [28]. In our study, we observed a decrease in inflammatory reactions and an increase in proliferative processes following laser treatment, indicating that cells responded positively to LLLT, such as per Re Popii et al. (2011) [28].

Although low-power laser irradiation has been shown to stimulate bone neoformation [20, 22, 25, 27, 29, 33, 39], there is no consensus about the parameters for its use, once its effects depend upon the intensity, frequency, type, and time of application [16, 22, 27-29, 33, 37, 40]. Some authors suggest that the frequency and the number of sessions applied influence the results $[16,41]$. The dose of radiation used in our study was of $4 \mathrm{~J} / \mathrm{cm} 2$ in each site, in line with several studies that suggest that doses of energy between 1 and $5 \mathrm{~J} /$ $\mathrm{cm} 2$ induce positive effects on bone and skin tissues [16, 25], and a total treatment dose of $112 \mathrm{~J} / \mathrm{cm} 2$ was applied around the cavity, being similar to the total dose of Scalize et al. (2015) [33] and Ré Poppi et al. (2011) [28].

The therapeutic use of low laser power to accelerate new bone formation within titanium scaffolds is very important, especially in osteoporotic rats, as it is known to provide a significant increase in life expectancy. Furthermore, LLLT could be an alternative treatment of this condition in humans.

\section{Conclusions}

Based on our methodology and results, we found that lowlevel laser therapy (780 $\mathrm{nm}$ laser GaAlAs) improves and accelerates bone repair within titanium scaffolds in both ovariectomized and healthy rats when compared to animals not submitted to radiation. Thus, LLLT is a valuable tool for better new bone formation in bone engineering tissue.

Acknowledgments This study was supported by research grants 2008/05619-0 and 2008/09867-9, awarded by the State of São Paulo Research Foundation (FAPESP), Brazil. The authors would also like to thank CAPES (Coordenação de Aperfeiçoamento de Pessoal de Nível Superior), for the Masters Scholarships awarded during this study.

Compliance with ethical standards This study was approved by the Ethics in Research Committee of the Graduate School of Dentistry of Sao Jose dos Campos, UNESP (process number 040/2007).

\section{References}

1. Vasconcellos LM, Oliveira FN, Leite DO, Vasconcellos LG, do Prado RF, Ramos CJ, Graça ML, Cairo CA, Carvalho YR (2012) Novel production method of porous surface Ti samples for biomedical application. J Mater Sci Mater Med 23(2):357-364. doi:10. 1007/s10856-011-4515-0

2. Guo Z, Iku S, Mu L, Wang Y, Shima T, Seki Y, Li Q, Kuboki Y (2013) Implantation with new three-dimensional porous titanium web for treatment of parietal bone defect in rabbit. Artif Organs 37(7):623-628. doi:10.1111/aor.12058

3. Van der Stok J, Van der Jagt OP, Amin Yavari S, De Haas MF, Waarsing JH, Jahr H, Van Lieshout EM, Patka P, Verhaar JA, Zadpoor AA, Weinans H (2013) Selective laser melting-produced porous titanium scaffolds regenerate bone in critical size cortical bone defects. J Orthop Res 31:792-799. doi:10.1002/jor.22293

4. Vasconcellos LM, Oliveira MV, Graça ML, Vasconcellos LG, Cairo CA, Carvalho YR (2008) Design of dental implants, influence on the osteogenesis and fixation. J Mater Sci Mater Med 19(8):28512857. doi:10.1007/s10856-008-3421-6

5. Wazen RM, Lefevre L-P, Baril E, Nanci A (2010) Initial evaluation of bone ingrowth into a novel porous titanium coating. J Biomed Mater Res B Appl Biomater 94(1):64-71. doi:10.1002/jbm.b. 31624

6. Xu J, Weng XJ, Wang X, Huang JZ, Zhang C, Muhammad H, Ma X, Liao QD (2013) Potential use of porous titanium-niobium alloy in orthopedic implants: preparation and experimental study of its biocompatibility in vitro. PLoS One 8(11):e79289. doi:10.1371/ journal.pone.0079289

7. Otsuki B, Takemoto M, Fujibayashi S, Neo M, Kokubo T, Nakamura T (2006) Pore throat size and connectivity determine bone and tissue ingrowth into porous implants: three-dimensional micro-CT based structural analyses of porous bioactive titanium implants. Biomaterials 27:5892-5900

8. Deporter DA, Watson PA, Pilliar RM, Pharoah M, Smith DC, Chipman M, Locker D, Rydall A (1996) A prospective clinical study in humans of an endosseous dental implant partially covered with a powder-sintered porous coating: 3- to 4-year results. Int J Oral Maxillofac Implants 11:87-95

9. Pilliar RM, Deporter DA, Watson PA, Todescan R (1998) The endopore implant-enhanced osseointegration with a sintered porous-surfaced design. Oral Health 7:61-64 
10. An YB, Lee WH (2006) Synthesis of porous titanium implants by environmental-electro-discharge-sintering process. Mater Chem Phys 95:242-247

11. Variola F, Brunski JB, Orsini G, Tambasco de Oliveira P, Wazen R, Nanci A (2011) Nanoscale surface modifications of medically relevant metals: state-of-the art and perspectives. Nanoscale 3(2):335353. doi:10.1039/c0nr00485e

12. Genant HK, Cooper C, Poor R, Reid I, Ehrlich G, Kanis J (1999) Interim report and recommendations of the world Health Organization task-force for osteoporosis. Osteoporos Int 10(4): 259-264

13. Marco F, Milena F, Gianluca G, Vittoria O (2005) Peri-implant osteogenesis in health and osteoporosis. Micron 36(7-8):630-644

14. Barbas A, Bonnet AS, Lipinski P, Pesci R, Dubois G (2012) Development and mechanical characterization of porous titanium bone substitutes. J Mech Behav Biomed Mater 9:34-44. doi:10. 1016/j.jmbbm.2012.01.008

15. Teixeira LN, Crippa GE, Lefebvre LP, De Oliveira PT, Rosa AL, Beloti MM (2012) The influence of pore size on osteoblast phenotype expression in cultures grown on porous titanium. Int J Oral Maxillofac Surg 41:1097-1101. doi:10.1016/j.ijom.2012.02.020

16. Khadra M (2005) The effect of low level laser irradiation on implant-tissue interaction. In vivo and in vitro studies. Swed Dent J Suppl 172:1-63

17. Freitas IGF, Baranauskas V, Cruz-Hofling MA (2000) Laser effects on osteogenesis. Appl Surf Sci 154-155:548-554

18. Fukuhara E, Goto T, Matayoshi T, Kobayashi S, Takahashi T (2006) Optimal low-energy laser irradiation causes temporal G2/ M arrest on rat calvarial. J Calcif Tissue Int 79(6)

19. Pereira CL, Sallum EA, Nociti FH Jr, Moreira RW (2009) The effect of low-intensity laser therapy on bone healing around titanium implants: a histometric study in rabbits. Int J Oral Maxillofac Implants 24(1):47-51

20. Boldrini C, de Almeida JM, Fernandes LA, Ribeiro FS, Garcia VG, Theodoro LH, Pontes AE (2013) Biomechanical effect of one session of low-level laser on the bone-titanium implant interface. Lasers Med Sci 28(1):349-352. doi:10.1007/s10103-012-1167-3

21. Obradovic RR, Kesic LG, Pesevska S (2009) Influence of low-level laser therapy on biomaterial osseointegration: a mini-review. Lasers Med Sci 24(3):447-451. doi:10.1007/s10103-008-0573-Z

22. Vasconcellos LM, Barbara MA, Deco CP, Junqueira JC, do Prado RF, Anbinder AL, Vasconcellos LG, Cairo CA, Carvalho YR (2014) Healing of normal and osteopenic bone with titanium implant and low-level laser therapy (GaAlAs): a histomorphometric study in rats. Lasers Med Sci 29(2):575-580. doi:10.1007/s10103013-1326-1

23. Vasconcellos LM, Leite DO, Oliveira FN, Carvalho YR, Cairo CA (2010) Evaluation of bone ingrowth into porous titanium implant: histomorphometric analysis in rabbits. Braz Oral Res 24(4):399-405

24. Salgado AJ, Coutinho OP, Reis RL (2004) Bone tissue engineering: state of the art and future trends. Macromol Biosci 4(8):743-765

25. Gerbi M, Pinheiro ALB, Marzola C, Limeira Júnior FA, Soares AO, Carvalho LCB et al (2005) Assessment of bone repair associated with the use of organic bovine bone and membrane irradiated at 830 nm. Photomed Laser Surg 23:382-388

26. García-Gareta E, Hua J, Rayan F, Blunn GW (2014) Stem cell engineered bone with calcium-phosphate coated porous titanium scaffold or silicon hydroxyapatite granules for revision total joint arthroplasty. J Mater Sci Mater Med 25(6):1553-1562. doi:10. 1007/s10856-014-5170-z

27. Pires-Oliveira DA, Oliveira RF, Amadei SU, Pacheco-Soares C, Rocha RF (2010) Laser $904 \mathrm{~nm}$ action on bone repair in rats with osteoporosis. Osteoporos Int 21:2109-2114. doi:10.1007/s00198010-1183-8

28. Ré Poppi R, Da Silva AL, Nacer RS, Vieira RP, de Oliveira LV, Santos de Faria N Jr, de Tarso Camilo Carvalho P (2011) Evaluation of the osteogenic effect of low-level laser therapy $(808 \mathrm{~nm}$ and 660 $\mathrm{nm}$ ) on bone defects induced in the femurs of female rats submitted to ovariectomy. Lasers Med Sci 26(4):515-522. doi:10.1007/ s10103-010-0867-9

29. Aras MH, Bozdag Z, Demir T, Oksayan R, Yanık S, Sökücü O (2015) Effects of low-level laser therapy on changes in inflammation and in the activity of osteoblasts in the expanded premaxillary suture in an ovariectomized rat model. Photomed Laser Surg 33(3): 136-144. doi:10.1089/pho.2014.3820

30. Lelovas PP, Xanthos TT, Thoma SE, Lyritis GP, Dontas IA (2008) The laboratory rat as an animal model for osteoporosis research. Comp Med 58(5):424-430

31. Pesce V, Speciale D, Sammarco G, Patella S, Spinarelli A, Patella V (2009) Surgical approach to bone healing in osteoporosis. Clin Cases Miner Bone Metab 6:131-135

32. Kalu DN (1991) The ovariectomized rat model of postmenopausal bone loss. Bone Miner 15(3):175-191, Review

33. Scalize PH, de Sousa LG, Regalo SC, Semprini M, Pitol DL, da Silva GA, de Almeida CJ, Coppi AA, Laad AA, Prado KF, Siessere S (2015) Low-level laser therapy improves bone formation: stereology findings for osteoporosis in rat model. Lasers Med Sci 30(5): 1599-1607. doi:10.1007/s10103-015-1773-y

34. Li M, Shen Y, Wronski TJ (1997) Time course of femoral neck osteopenia in ovariectomized rats. Bone 20(1):55-61

35. Prado RF, Silveira VÁ, Rocha RF, Vasconcellos LM, Carvalho YR (2012) Effects of experimental osteoporosis and low calcium intake on postextraction sockets of rats. Int J Exp Pathol 93(2):139-147. doi:10.1111/j.1365-2613.2012.00809.x

36. Jee WS, Yao W (2001) Overview: animal models of osteopenia and osteoporosis. J Musculoskelet Neuronal Interact 1(3):193-207

37. Nissan J, Assif D, Gross M, Yaffe A, Binderman I (2006) Effect of low intensity laser irradiation on surgically created bony defects in rats. J Oral Rehabil 33:619-624

38. Saad A, El Yamany M, Abbas O, Yehia M (2010) Possible role of low level laser therapy on bone turnover in ovariectomized rats. Endocr Regul 44(4): 155-163

39. Pretel H, Lizarelli RF, Ramalho LT (2007) Effect of low-level laser therapy on bone repair: histological study in rats. Lasers Surg Med 39(10):788-796

40. Gomes FV, Mayer L, Massotti FP, Baraldi CE, Ponzoni D, Webber JB, de Oliveira MG (2015) Low-level laser therapy improves periimplant bone formation: resonance frequency, electron microscopy, and stereology findings in a rabbit model. Int $\mathrm{J}$ Oral Maxillofac Surg 44(2):245-251. doi:10.1016/j.ijom.2014.09.010

41. Ozawa Y, Shimizu N, Kariya G, Abiko Y (1998) Low-energy laser irradiation stimulus bone nodule formation at early stages of cell culture in rat calvarial cells. Bone 22:347-354 